\section{Depression of spontaneous activity in goldfish by magnesium pemoline*}

\author{
LARRY P. GONZALEZ† and S. THOMAS ELDER \\ Louisiana State University in New Orleans, New Orleans, La. 70122
}

Two groups were used in an experiment designed to assess the influence of magnesium pemoline on spontaneous activity levels in goldfish. The first group of 36 was used to evaluate the stability of spontaneous activity over three $1 / 2-h$ trials, and the second group of 60 , which was divided into 10 subgroups, received the drug treatment. The suspension was administered intracranially, and dosages varied from 0.005 to $2.5 \mathrm{mg}$. The results showed that spontaneous activity was depressed significantly under dose levels of 0.5 to 2.5 , but no observable effect was seen at dosages of 0.005-0.1.

M a g n es i u m p moli ne (Cylert-Abbott 30400), a combination of magnesium hydroxide and pemoline (2-imino-5-phenyl-4-oxazolidinone, Abbott 13397), has been reported to facilitate the production of RNA in vivo and in vitro. For this reason, much attention has been directed toward the effects of this drug upon learning and retention of various tasks. Although the results remain highly controversial, many investigators (e.g., Plotnikoff, 1966; Doty \& Howard, 1968) have reported an increased rate of acquisition and prolonged retention following the administration of this compound.

Most of these studies, however, have employed tasks involving the acquisition of active responses, and it is not clear whether observed increments in performance were due to increased learning or to a general increase in activity. Some have suggested (e.g., Talland, 1966; Powell, Martin, \& Kamano, 1967) that the facilitating effect of magnesium pemoline upon performance was the result of its action as a central nervous system stimulant; and it has been shown to increase the amount of spontaneous activity in rats (Beach \& Kimble, 1967), mice, dogs, cats, and monkeys (Plotnikoff, Will, \& Dietzler, 1969).

Since the goldfish (Carassius auratus) has become an increasingly popular subject in studies involving the behavioral effects of drugs, the present study was undertaken to determine the effect of magnesium pemoline injections upon the spontaneous activity rate of goldfish. Such a study is necessary for the meaningful interpretation of further research involving magnesium pemoline and its

*Direct reprint requests to $S$. Thomas Elder, Department of Psychology, LSUNO-Lakefront, New Orleans, La. 70122.

+Now at the University of Texas at Houston (GSBS). effect upon acquisition and retention of goldfish behavior.

\section{SUBJECTS}

The Ss of this experiment were 96 goldfish (Carassius auratus), $17-20 \mathrm{~cm}$ in total length and an average weight of $75 \mathrm{~g}$. They were divided randomly into two groups, one of which consisted of $36 \mathrm{Ss}$ and the second of which consisted of $60 \mathrm{Ss}$ divided into 10 subgroups of 6 each.

All Ss were maintained in individual 5 -gallon aquaria $\left(16^{1 / 2} \times 32 \times 20^{1 / 2} \mathrm{~cm}\right)$ equipped with continuously operating aerators and filters. The aquatic medium was aged dechlorinated tap water at approximately $20^{\circ} \mathrm{C}$.

\section{APPARATUS}

The experimental equipment consisted of a wooden frame into which a 5-gal aquarium could be placed. Three photoelectric relays were positioned at equal distances along the length of the tank, and accompanying light sources were Output from these photoelectric relays was used to operate a mechanical counter, the readout from which served as the measure of activity.

\section{PROCEDURE}

All Ss in both groups received 4 days of adaptation to the experimental situation. An $\mathbf{S}$ in its home tank was transferred to the experimental room, and the $\tan k$ was positioned in the photocell frame. An overhead 100-W light and the photoelectric relays and light sources were turned on, while the $\mathrm{S}$ was allowed to move freely for a 5 -min period, during which its activity was recorded. This constituted Trial 1 . At the end of the period, the $S$, still in its home tank, was removed from the room for $1 / 2 h$ and then replaced in the photocell frame for a second 5-min period, during which activity was recorded again. This procedure was repeated once more $1 / 2 \mathrm{~h}$ later so that a total of three 5-min trials was given at $1 / 2$ - $h$ intervals.

On the fifth day, the first sample positioned on the opposite side. was tested as on Days 1-4. Similarly, activity measures were taken on throse in the second group, with the exception that $S$ s received previously designated injections immediately following Trial 1. Injections were performed in accordance with Agranolf \& Klinger's (1964) procedure. The cranium was penetrated at the medial suture and in line with the posterior margin of the orbits. A $1.3-\mathrm{mm} 30$-ga needle was inserted to a depth of $2 \mathrm{~mm}$ at an angle of $45 \mathrm{deg}$ to the surface and was directed posteriorly. This procedure placed the tip of the needle in the midline over the tecta. A 100 microliter Hamilton syringe was used; the volume of the injected fluid was 10 microliters.

Nine of the 10 subgroups of Ss received injections of magnesium pemoline suspended in $0.25 \%$ carboxy methyl cellulase. The dosages were $0.005,0.01,0.05,0.1,0.5,1.0,1.5$, 2.0 , and $2.5 \mathrm{mg}$. A dosage of 1.0 and $1.5 \mathrm{mg}$ was comparable to dosages that have been reported to facilitate learning in rats (Plotnikoff, 1966). The 10 th subgroup of $S$ s (control) received an injection of 10 microliters of the suspension fluid alone.

Following injection, two activity counts (Trials 2 and 3 ) were recorded at $1 / 2$ - $h$ intervals, as in the adaptation procedure. Each $S$ received only one injection.

\section{RESULTS}

Raw activity scores from Group 1 obtained over Trials 1-3 on Day 5 were analyzed first to see if there were any extraexperimental differences across trials. None was found, and it was assumed that adaptation to the apparatus and procedure had occurred by Day 5 .

Raw activity scores from the second group were analyzed by use of a $2 \mathbf{x}$ 10 analysis of variance. This yielded a significant treatment effect $(F=2.07$, $\mathrm{df}=2 / 70, \mathrm{p}<.05)$, a significant trials main effect $(F=7.67, \mathrm{df}=2 / 100$, $p<.001)$, and a significant Treatments by Trials interaction $(F=$ $2.98, \mathrm{df}=18 / 100, \mathrm{p}(.001)$. The latter effect has been illustrated in Fig. 1. The application of Duncan's range test revealed that those groups which received at least $0.5 \mathrm{mg}$ or more of magnesium pemoline (i.e., $0.5,1.0$. $1.5,2.0$, or $2.5 \mathrm{mg}$ ) were significantly less active than the control subgroup. Differences between the control and subgroups which received 0.1 and $0.005 \mathrm{mg}$ were not statistically reliable. Significant differences across trials were found for all the drus conditions except $0.005-0.1 \mathrm{mg}$, but not for the control subgroup.

\section{DISCUSSION}

When injected intracranially. dosages as large as $0.5 \mathrm{mg}$ or larger 


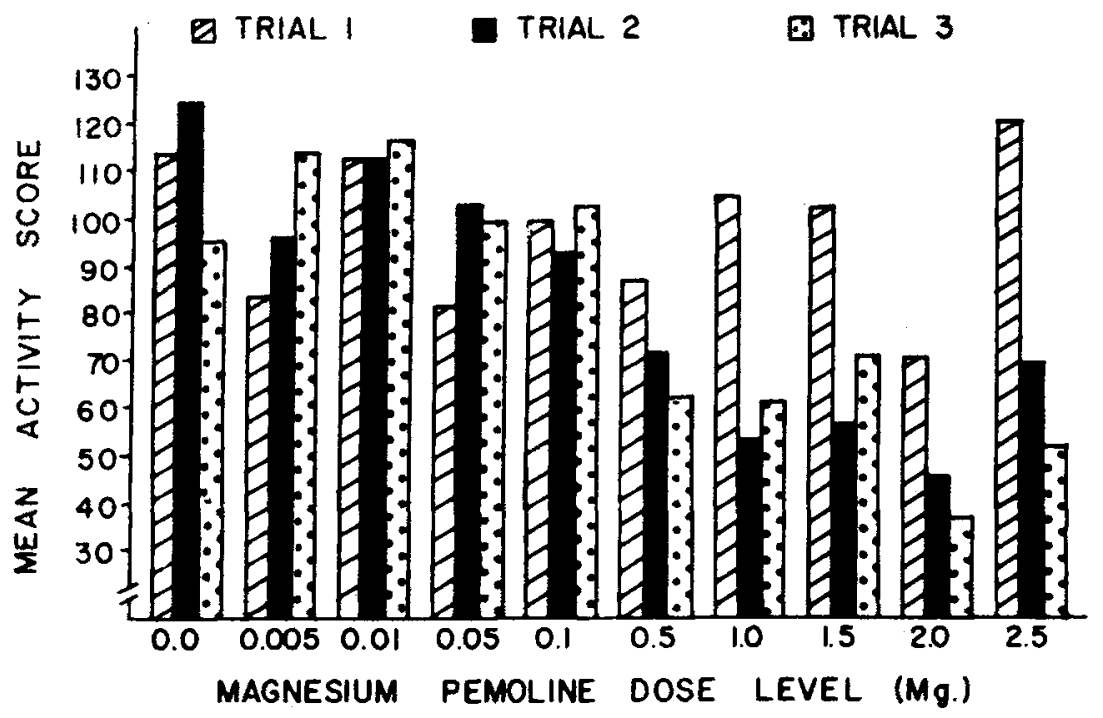

Fig. 1. Comparison of mean activity scores for the $\mathbf{1 0}$ subgroups over trials.

suppressed activity in goldfish; dosages between 0.005 and $0.1 \mathrm{mg}$ did not produce an observable effect. In view of the fact that volume was constant across all groups, such a finding mitigates against the argument that mechanical stimulation may have accounted for these data.

The results of this study are not in agreement with the previous data (e.g., Beach \& Kimble, 1967; Plotnikoff, Hill, \& Dietzler, 1969), which showed that magnesium pemoline increased spontaneous activity in mammals. There are a number of possible reasons for this discrepancy. First, intracranial injections were used in this study; intraperitoneal injections were used in most of the experiments with mammals. Secondly, the present data may represent a basic species difference between fish and mammals; magnesium pemoline may decrease activity in fish and increase activity in rats, mice, dogs, cats, and monkeys.

Finally, it may be useful to note that dosages up through $0.1 \mathrm{mg}$ had no significant effect upon activity rate. These dosage levels could thus be employed in studies testing the effects of magnesium pemoline upon learning in the goldfish without the problem of its affecting overt spontaneous activity.

\section{REFERENCES}

AGRANOFF, B. W., \& KLINGER, P. D Puromycin effect on memory fixation in the gold fish. Science, 1964, 146, $952-953$.

BEACH, G., \& KIMBLE, D. P. Activity and responsitivity in rats after magnesium pemoline injections. Science, 1967,155 . 698-701.

DOTY B, \& HOWARD, $s$ Facilitative effects of post-trial magnesium pemoline on avoidance conditioning in relation to problem difficulty. Life Science, 1968, 7. 591-597.

PLOTNIKOFF, $N$ Magnesium pemoline: Enhancement of learning and memory of a conditioned avoidance response. Science, 1966, 151, 703-704.

PLOTNIKOFF, N WILL, $F$ \& DITZLER W. Stimulant activity of pemoline and magnesium hydroxide. Archives Internationales de Pharmacodynamie et de Therapie (Ghent), 1969, 181, 441-458.

POWELL, B. J., MARTIN, L. K., \& KAMANO, D. K. Magnesium pemoline: Effects of training vs testing of an avaidance response. Psychonomic Science, $1967,8,205.206$.

TALLAND, G. A. Improvement of sustained attention with Cylert. Psychonomic Science, 1966, 6, 493-494. 